\title{
Ciberespacio y ciudadanos: una mirada a través de los ayuntamientos españoles
}

\author{
Antonio García Jiménez* \\ Beatriz Catalina García*
}

Recibido: 15 de mayo de 2014 - Aprobado: 16 de octubre de 2014

\section{Resumen}

El ciberespacio constituye un marco idóneo para incentivar la participación ciudadana en la gestión de lo público. Un adecuado diseño y contenidos con herramientas de sencillo acceso para la interactividad comunicacional en páginas web facilitan la comprensión de los usuarios, y que estos tomen parte activa en el desarrollo político y administrativo de una determinada zona geográfica. En este contexto, la administración municipal, considerada la más cercana al ciudadano en España, dispone en Internet de un medio óptimo y económico para facilitar la exposición de opiniones, ya sean sugerencias, quejas u opiniones que procuren corregir posibles errores cometidos por los gestores públicos. No cabe duda de que la E-Administración facilita un gran número de servicios al ciudadano sin encontrarse con el obstáculo de la distancia física. También reconocemos la interactividad que entraña, pero se trata únicamente de rellenar espacios que son prefijados por el ayuntamiento, por lo que sigue habiendo un emisor y un receptor claramente definidos. Herramientas sencillas que pueden ser aplicables para incitar la participación activa de los ciudadanos en la web municipal son las generadas para que estos aporten contenidos audiovisuales, gráficos y textuales, los cuales aluden a aspectos que tienen que ver con el municipio correspondiente, enriquecen el contenido de la web y, por extensión, potencian la implicación política y comunicación ciudadana.

Palabras clave: ciberespacio, participación ciudadana, gestión pública, E-Administración, web municipal.

\footnotetext{
* Doctor en Ciencias de la Información por la Universidad Complutense (1996). Profesor titular del área de periodismo de la Universidad Rey Juan Carlos, Madrid-España; y ex Decano de la Facultad de Ciencias de la Comunicación de la misma Universidad. Ha participado y dirigido diferentes proyectos de investigación relacionados con Internet (usos y riesgos en adolescentes, sistemas de información y organización de información en web, género e Internet), con la generación automática del lenguaje y con la representación de la mujer en los medios de comunicación. Dirección postal: Calle Tulipán, s/n, 28933 Móstoles, Madrid, España. Correo electrónico: antonio.garcia@urjc.es

** Beatriz Catalina García es profesora visitante del Departamento de Ciencias de la Comunicación I de la Facultad de Ciencias de la Comunicación de la Universidad Rey Juan Carlos de Madrid. Es Doctora en Comunicación y Ciencias sociales por la misma Universidad, y su tesis, titulada "Estudio sobre la interactividad en las web de los Ayuntamientos de España" fue dirigida por Antonio García. Dirección postal: Calle Tulipán, s/n, 28933 Móstoles, Madrid, España. Correo electrónico: beatriz.catalina@urjc.es.
} 


\title{
Cyberspace and citizens: a view to Spanish town halls
}

\author{
Antonio García Jiménez* \\ Beatriz Catalina García*
}

\section{A bstract}

Cyberspace makes an ideal framework to promote citizen participation in public management. A suitable design and suitable contents with tools of easy access for interactive communication on web pages facilitate the users' understanding, and in that way they can have an active role in the administrative development of a specific geographical area. On this context, a town hall has on Internet as an ideal and economic mean that facilitates the presentation of opinions, suggestions which intend to correct public servants' mistakes.Without hesitation,Emanagement facilitates a great number of services to the citizen without the obstacles involving the physical distance. We also recognize the interaction which internet has, but it only tries to fill in spaces set by the town hall,so there are still a well defined transmitter and a well defined recipient. Simple tools which can be applicable in order to foster citizens' active participation in the town hall's web page so that they contribute with audiovisual, graphic and text contents concerning the town's issues. Thus, the content of the web page is increased and the political involvement and citizen communication are powered.

Keywords: Cyberspace, citizen participation, public management, e-management, town's web.

Doctor in Information Sciences at Universidad Complutense (1996). Professor of Journalism at Universidad Rey Juan Carlos, Madrid-Spain and former Dean of the Faculty of Communication Sciences at this university. He has participated and directed different projects which deal with Internet (uses and risks in teenagers, information systems and information management on web, gender and Internet), with the automatic language generation and women's involvement in mass media. Address: Calle Tulipán, s/n, 28933 Móstoles, Madrid, España. Email: antonio.garcia@urjc.es.

** Beatriz Catalina García is Visiting Profesor at the Department of Communication Sciences at Universidad Rey Juan Carlos. She holds a Phd in Communication and Social Sciences from this university, and her thesis, "Estudio sobre la interactividad en las web de los Ayuntamientos de España" (Study on interaction of Spanish townhalls' web pages) was directed by Antonio García. Address: Calle Tulipán, s/n, 28933 Móstoles, Madrid, España. Email: beatriz.catalina@urjc.es. 


\title{
Le cyberespace et les citoyens : un regard à travers des municipalités espagnoles
}

\author{
Antonio García Jiménez* \\ Beatriz Catalina García*
}

\section{Résumé}

Le cyberespace constitue un cadre idéal pour stimuler la participation citadine dans la gestion du public. Un adéquat dessin et des contenus avec outils d'accès simple pour l'interactivité communicationnelle aux pages Web fournissent la compréhension des utilisateurs, et que ceux-ci prennent une active partie dans le développement politique et administratif d'une zone déterminée géographique. Dans ce contexte, l'administration municipale, considérée la plus proche au citoyen en Espagne, dispose dans l'Internet d'un milieu parfait et économique pour faciliter l'exposition d'opinions, soyez déjà des suggestions, des plaintes ou opinions qui essaient de corriger des erreurs possibles commises par les gérants publics. Il ne fait aucun doute que la E-Administration fournisse un grand nombre de services au citoyen sans se trouver avec l'obstacle de la distance physique. On reconnais aussi l'interactivité qu'elle enfouit, mais il s'agit de remplir uniquement les espaces qui sont préfixés par la municipalité parce qu'il continue d'y avoir un récepteur et un émetteur clairement définis. Les outils simples peuvent être applicables pour inciter l'active participation des citoyens dans la web municipal sont les générées pour que ceux-ci apportent des contenus audiovisuels, graphiques et textuels, lesquels font allusion à des aspects qui ont à voir avec la municipalité correspondante, ils enrichissent le contenu d'un web et, par extension, ils renforcent l'implication politique et la communication citadine.

Mots clés: Le Cyberespace, la participation citadine, la gestion publique, e- administration, le web municipal.

\footnotetext{
* Docteur en Sciences de l'Information par l'Université Complutense (1996). Professeur Titulaire du domaine de Journalisme de l'Université Rey Juan Carlos, Madrid-España et un ex-Doyen de la Faculté de Sciences de la Communication de la même université. II a participé et dirigé différents projets de recherche en relation l'Internet (des usages et des risques chez des adolescences, des systèmes d'information et organisation d'information sur la web, le genre et l'Internet), avec la génération automatique du langage et avec la représentation de la femme dans les médias. Adresse: Calle Tulipán, s/n, 28933 Móstoles, Madrid, España. Email: antonio.garcia@urjc.es.

** Beatriz Catalina García Est professeur invitée du Département de Sciences de la Communication I de la Faculté de Sciences de la Communication de l'Université Rey Juan Carlos de Madrid. Elle est un Docteur en Communication et Sciences sociales par la même université, et sa thèse, intitulée «Des études de l'interactivité dans le web des conseils municipaux d'Espagne» elle a été dirigée par Antonio García. Adresse: Calle Tulipán, s/n, 28933 Móstoles, Madrid, España. Email: beatriz.catalina@urjc.es.
} 


\section{Introducción}

El ciberespacio constituye un marco idóneo para incentivar la participación ciudadana en la gestión de lo público. Un adecuado diseño y contenidos con herramientas de sencillo acceso para la interactividad comunicacional en páginas web facilitan la comprensión del usuario, que estos tomen parte activa y no sean solo meros oyentes que no opinan, ni demandan ni intervienen en el desarrollo político ni administrativo de una determinada zona geográfica.

En este contexto, la administración municipal, considerada la más cercana al ciudadano en España, dispone en Internet de un medio óptimo y económico para facilitar la exposición de opiniones, ya sean sugerencias, quejas u opiniones que procuren corregir posibles errores cometidos por los gestores públicos, con la intención de que estos ofrezcan oportunidades y servicios más consonantes a la demanda de la población y que cuenten con el máximo consenso posible. En una óptima comunicación web con el ayuntamiento, el ciudadano no es únicamente un interlocutor, sino que se convierte en un descubridor y, en algunos casos, en un inventor.

Los resultados que expondremos en este texto, corresponden a la cuantificación y análisis de contenido de la tesis doctoral defendida por la coautora de este texto sobre las herramientas utilizadas por los ayuntamientos de España en sus web oficiales, para incentivar la participación ciudadana. Para su desarrollo se obtuvo una muestra de 351 municipios españoles (incluidas las 51 capitales de provincia), de un universo de 4.670 ayuntamientos que disponen de página web.

El objetivo era clarificar si los ayuntamientos aplican en sus webs oficiales las herramientas adecuadas para incentivar la participación ciudadana. Este análisis se acompaña de la cuantificación de aquellas herramientas digitales que incitan a la comunicación entre ciudadanía y administración municipal. También se ha tomado en consideración los elementos innovadores que, fomentando la interactividad, permiten que los actores de este contexto comunicativo no queden prefijados en los roles estereotipados y, en cierto modo, anacrónicos, de emisor y receptor.

Consideramos que en una página institucional no se deben descartar ninguna de las fórmulas disponibles que fomentan la participación ciudadana en la comunicación por Internet. No cabe duda de que la E-Administración facilita un gran número de servicios al ciudadano sin encontrarse con el obstáculo de la distancia física. También reconocemos la interactividad que entraña, pero se trata únicamente de rellenar espacios que son prefijados por el ayuntamiento, por lo que sigue habiendo un emisor y un receptor claramente definidos.

Herramientas sencillas que pueden ser aplicables para incitar a la participación activa de los ciudadanos en la web municipal son las generadas para que estos aporten contenidos audiovisuales, gráficos y textuales, los cuales aluden 
a aspectos que tienen que ver con el municipio correspondiente, enriquecen el contenido de la web y, por extensión, potencian la implicación política y comunicación ciudadana. En el mencionado estudio se comprobó si en cada página web analizada se ofrecían este tipo de herramientas, habituales y generalizadas en todo el universo Internet, para fomentar la comunicación con la administración pública; además se cuantificaron alternativas novedosas que mantienen la interactividad entre el ciudadano y el ayuntamiento, o en el seno de la propia ciudadanía.

\section{Estado de la cuestión}

Los ayuntamientos en España constituyen los entes más modestos de toda la estructura orgánica pública en varios aspectos: en el referido a sus fondos económicos, en su cantidad poblacional y en su capacidad legislativa. Este hecho no va en consonancia con la paulatina y cada vez mayor asunción de competencias ni tampoco con la identificación de los ciudadanos hacia la institución más estrecha que con otras administraciones. Sin embargo, la participación ciudadana y el denominado Open Government no deben ni pueden encontrar trabas en los problemas económicos y competenciales que tienen actualmente los ayuntamientos en España, sino todo lo contrario. El uso de Internet aumenta la posibilidad de participar reduciendo los costes que suponen la implicación activa de los ciudadanos en un Gobierno Abierto, al menos, "de usuarios habilidosos y experimentados, incluso en ausencia de motivaciones políticas" (Borge et al. 2012).

El creciente grado de insatisfacción de los ciudadanos por la política se traduce, entre otros fenómenos, en una alta abstención en las consultas populares y en una escasa afiliación en los diferentes colectivos. El Libro Blanco de la Gobernanza Europea (2001) $)^{1}$ pretende ofrecer pautas como el desarrollo de la transparencia, la coherencia, la eficacia, la apertura a la participación, la rendición de cuentas y la asunción de responsabilidades; todas ellas como elementos característicos de una buena gobernanza.

El propio sistema democrático ofrece instrumentos garantes para su efectividad en el caso de la transparencia, la rendición de cuentas o la asunción de responsabilidades. Sin embargo, la participación ciudadana ha tenido poco recorrido si se tienen en cuenta las diferentes clasificaciones que se han establecido al respecto en la cronología de la literatura científica. Desde la propuesta por Arnstein (1969) hasta otras más recientes, como la sugerida en el año 2000 por la International Association for Public Participation (IAP2) que sitúan la implicación ciudadana en los niveles más básicos. En el caso de Arnstein se englobaría, en el mejor de los casos, en un nivel intermedio: el Plano de la Participación Simbólica, por el cual se permite a la ciudadanía escuchar, tener voz e incluso que esta

1 Comisión Europea (2001). La gobernanza europea - Un Libro Blanco. [COM (2001) 428 final - Diario Oficial C 287 de 12/10/2001]. 
sea escuchada; muy distante a lo que se espera de una verdadera y efectiva participación-Plano del poder ciudadano-por la que el individuo toma decisiones mediante mecanismos de negociación y de acuerdo. En la clasificación de IAP2 (por este orden: información, consulta, implicación, colaboración y delegación), la actual participación se vendría a situar en un grado consultor con discretas conquistas hacia la implicación. Paralelamente, el estudio publicado por el CIS "Ciudadanía, Participación y Democracia" (2002), refleja que solo el 2,7 \% de los españoles mayores de 18 años está adscrito y participa activamente en alguna asociación, ya sea política o de cualquier otro ámbito.

En la aportación de causas que conllevan a esta desidia, Llinares (2010, p. 51) apunta que la participación "tiene que ver más con una actitud y una forma de entender el rol que se debe jugar que con una forma concreta de practicarlo". La comunicación con el ciudadano puede ser potenciada a través de la web oficial de las administraciones, pero no con una mera página informativa que esté disponible en la red. Internet ofrece la posibilidad de plantear mensajes públicos, restringidos y personales, sin limitaciones espaciales o temporales. Investigadores como Evans y Campos (2013) apuntan la conveniencia de evaluar la percepción del público sobre las políticas, pero también es deseable evaluar las consecuencias sobre la percepción del público en torno a la política y a la administración a través del Open Government; de este modo, añaden, se podrá determinar la brecha entre la oferta pública y la demanda ciudadana.

Si planteamos una relación directa de la participación con la implicación de los ciudadanos en la formulación, ejecución y supervisión de las políticas públicas, Internet facilita esta labor: pero por si solo es imposible. Si nos ceñimos a los datos aportados por Nielsen (2011), el $10 \%$ de los usuarios de Internet produce contenidos, el 90 \% restante -a los que el autor denomina Lurckers- solo consumen esos contenidos. Encontramos, por tanto, que el acceso a un Gobierno Abierto de los ciudadanos se limita a una mera teoría. Una cuestión que se acentúa con la tesis de la normalización apuntada por Margolis y Resnick (2000) quienes consideran que, tras las expectativas que en un principio creó Internet, la actividad se ha ido normalizando y los individuos hacen en Internet lo que hacían ya presencialmente; en este sentido, Internet no moviliza a gente nueva, sino refuerza a los que ya participaban en política. Igualmente, se relaciona con ello la teoría de la movilización y del refuerzo desarrollada por Norris (2003), quien asegura que las Nuevas Tecnologías de la Información y la Comunicación son utilizadas preferentemente por aquellos ciudadanos y grupos sociales ya activamente implicados en los asuntos públicos.

Es evidente que, puesto en práctica de modo efectivo, el Open Government fortalece la democracia pero, para ello, es preciso un cambio de conducta bidireccional (de administradores y de ciudadanos) y que tiene que ver con el ámbito cultural, con la forma de ejecutar políticas, con la organización y con las formas de comunicarse. Freeman (2013) concluye que el creciente aumento de las poblaciones con acceso a Internet $y$, por ende, con nuevas formas de comunicación, obliga a los municipios a adoptar y utilizar estos métodos para incrementar la comunicación ciudadana. 
Es deseable, por tanto, que el punto de partida para el logro de ese cambio de conductas provenga de la propia administración pública y, en el caso que nos ocupa, de los ayuntamientos y de los responsables políticos municipales, quienes sería conveniente que tuvieran en cuenta lo que Surowiecki (2005) denominó Sabiduría de multitudes, o lo que Lévy (2004) consideró como La inteligencia colectiva. En otras palabras, la toma de conciencia por parte de los administradores de la capacidad que tienen los ciudadanos para proponer, e incluso desarrollar políticas activas. En este mismo contexto, Lehtonen y Mambere (2013) mostraron que los temas propuestos por los residentes en el municipio finlandés de Tampere, proporcionaron una base útil para explorar elementos de las tecnologías de la comunicación que facilitan formas de conocimiento en la planificación de las ciudades y en el desarrollo de los barrios.

Salvo algunas voces reticentes, casi excepcionales, la mayoría de los estudios consideran imprescindible la implicación social en el ámbito municipal. Como punto previo, Chaín, Muñoz Cañavate y Más Bleda (2008), centran su investigación en el desarrollo orgánico del ayuntamiento, lo que ha contribuido a incrementar la relación con los vecinos. Aseguran que el nuevo modelo administrativo local sigue siendo burocrático, si bien con una mayor flexibilización de las relaciones entre sus diferentes áreas. En consecuencia, esta realidad implica un mejor funcionamiento en un modelo de ayuntamiento cada vez más complejo que, por otra parte, evidencia un aumento en las aplicaciones online. No obstante, autores como Baldershein y Øgård (2008) defienden el carácter social que se debe imprimir a la participación, en detrimento del rasgo político que esta pueda poseer.

Precisamente, Sádaba (2010) atribuye la brecha digital a otras diferenciaciones sociales, educacionales, económicas o culturales, las cuales, en un mundo globalizado, han sido motivo de separación y marginación. Más cercano a nuestro ámbito de estudio, Voces-Merayo y Codina (2009), refiriéndose a Internet, destacan la importancia de la participación ciudadana en el desarrollo social, y aseguran, asimismo, que el éxito de una página web estriba en conocer al usuario, saber los perfiles que puede adoptar y satisfacer sus demandas, en definitiva, implementar una web útil, usable y accesible. Para conseguir estos objetivos, comunes también en otras investigaciones, Pineda de Alcázar (2009) se centra en la estructura que, en su opinión, facilita un espacio para las relaciones horizontales con consecuencias a largo plazo.

En aras de una perspectiva positivista, la participación social puede ser objetivamente cuantificable en diferentes aspectos y numerosos ámbitos (Salinas, 1988; Regil, 2001; Van Kaan y Bordewick, 2002). El aprovechamiento de este tipo de análisis reside en la medición de la eficacia que caracteriza a las propuestas y recursos, los cuales deben -o sería deseable- que incitaran a una implicación activa del individuo.

Por último, es obligado mencionar la denominada web 2.0, estrechamente enlazada con la comunicación del ciudadano, que ha sido objeto de numerosos 
estudios en los últimos años. Correa (2008) atribuye a este fenómeno "más cambios culturales que tecnológicos" y, en la misma línea, Ros-Martín (2008) afirma que una consecuencia de su implantación es la reelaboración de los sistemas de filtrado social que proporcionan al usuario una mayor capacidad de discernimiento. En relación con las administraciones públicas, Zappen, Harrison y Watson (2008) presentan las bondades que la web 2.0 puede tener para las administraciones públicas, puesto que pueden proporcionar el diseño de servicios que satisfagan la demanda cada vez mayor de usuarios de experiencias útiles y enriquecedoras. Flores y Rezende (2013), en referencia a la red Twitter, atribuyen a esta un gran potencial comunicacional entre el gobierno y los ciudadanos en numerosos niveles y en direcciones multidireccionales entre los usuarios.

\section{Una escasa apuesta por Internet}

A pesar de la generalización de usos en Internet ya perceptible a finales del siglo pasado, pudimos comprobar una década después, entre el 2009 y el 2010, que cerca de la mitad de los ayuntamientos, algo más de un $42 \%$ del total, no disponía aún de página web oficial (García, 2011). Del resto de municipios, se corroboró que en los mejores casos, están vinculados a webs más generalizadas gestionadas por determinadas empresas, pero cuyo mantenimiento (si es que existe) no depende de los gestores o administradores municipales. La división que se realizó para el estudio corresponde a la población censada y registrada en el Instituto Nacional de Estadística (tabla. 1).

Tabla 1. Población censada con y sin web

\begin{tabular}{|c|c|c|c|}
\hline POBLACIÓN & SIN WEB (\%) & CON WEB (\%) & TOTAL \\
\hline Menos de 101 hab. & $762(71,1 \%)$ & $311(28,9 \%)$ & 1.073 \\
\hline 101- 500 hab. & $1.676(61,6 \%)$ & $1.045(38,4 \%)$ & 2.721 \\
\hline 501-1.000 hab. & $452(42,4 \%)$ & $614(57,6 \%)$ & 1.066 \\
\hline 1.001-2.000 hab. & $298(32,1 \%)$ & $630(67,9 \%)$ & 928 \\
\hline 2.000-3.000 hab. & $119(22,9 \%)$ & $399(77,1 \%)$ & 518 \\
\hline 3.001-5.000 hab. & $77(15,3 \%)$ & $427(84,7 \%)$ & 504 \\
\hline 5.001-10.000 hab. & $38(6,9 \%)$ & $515(93,1 \%)$ & 553 \\
\hline 10.001-20.000 hab. & $20(5,6 \%)$ & $336(94,4 \%)$ & 356 \\
\hline 20.001-30.000 hab. & $0(0 \%)$ & $148(100 \%)$ & 148 \\
\hline $30.001-50.000$ hab. & $0(0 \%)$ & $100(100 \%)$ & 100 \\
\hline $50.001-100.000$ hab. & $0(0 \%)$ & $83(100 \%)$ & 83 \\
\hline 100.001-500.000 hab. & $0(0 \%)$ & $56(100 \%)$ & 56 \\
\hline Más de 500.000 hab. & $0(0 \%)$ & $6(100 \%)$ & 6 \\
\hline TOTAL & $3.442(42,4 \%)$ & $4.670(57,6 \%)$ & 8.112 \\
\hline
\end{tabular}

Fuente: elaboración propia. 
Estamos, por tanto, ante un primer dato que, pese a su aparente obviedad, no deja de ser importante: conforme aumenta al nivel poblacional, se incrementa la cantidad de ayuntamientos que disponen de páginas web institucionales. Sin embargo, se ha observado que la cantidad de web no viene acompañada por un paulatino incremento cualitativo en lo que se refiere al grado de interactividad y, en consecuencia, la aceptación de los ciudadanos por parte de la administración local como participantes en la generación y desarrollo de un "ayuntamiento virtual", por el cual se pueda conseguir una participación democrática cuasi directa del usuario en la vida y avances de su propio municipio.

\section{Proliferan las redes sociales y los blogs}

En el caso de los ayuntamientos, la finalidad de introducirse en Internet es ofrecer un recurso más para el avance de la ciudadanía, pilar básico de cualquier tipo de administración pública. Si se pretende que en la era democrática y con el meteórico progreso de las nuevas tecnologías, sean unos pocos los que dirijan los destinos de todos los demás, las páginas web municipales se quedarán en un recurso prácticamente olvidado por el ciudadano que buscará otras vías de escape en Internet con mejores oportunidades para alzar su voz.

Este extremo ya se está produciendo con la proliferación de las denominadas "redes sociales". De hecho, existen municipios que sustituyen la interactividad en la propia página por un enlace hacia un vínculo de estas redes, fundamentalmente Facebook o Twitter que son las más populares. En otras palabras: hay ayuntamientos que prefieren fomentar páginas ajenas a la suya propia, relegando esta a un segundo plano para la participación y reservándola para una información unilateral tradicional con emisor y receptor plenamente identificados.

Incluso hay responsables políticos, en su mayoría los propios alcaldes, que protagonizan su propio blog y que en muchos casos disponen también de un vínculo en la propia página municipal. En estos blogs se generan diversos foros propuestos por el regidor quien, por supuesto, tiene la parte protagonista en lo que se refiere a exponer opiniones, mientras que las impresiones y valoraciones de los ciudadanos van a la zaga.

Se ha comprobado que una gran cantidad de municipios, independientemente de su nivel poblacional, utiliza con bastante frecuencia la página Foro-Ciudad (www.foro-ciudad.com), incluso llega a ser parte del contenido en los cursos formativos de iniciación a las nuevas tecnologías que se imparten en los centros públicos de acceso a Internet. El Foro-Ciudad se ha convertido en una alternativa a las localidades que carecen de web municipal, o como un contrapeso a las propias páginas excesivamente institucionales y con escasa interactividad para los ciudadanos. Ésta es una de las razones por la que muchos ayuntamientos eligen esta opción, desechando la creación de una web propia que potencie una mayor identificación para el ciudadano, en comparación al matiz tan generalista aportado por el Foro. 


\section{Factores que potencian o impiden la interactividad en una web municipal}

\section{La posible reticencia política}

La creación de una página web que potencie la implicación de los vecinos debe pasar inexorablemente por la apuesta, la voluntad y el interés del administrador (en este caso, del ayuntamiento) para conseguir este objetivo. A pesar de que los ayuntamientos democráticos en España están ya consolidados tras casi 40 años, cuesta aún mucho trabajo implicar a los vecinos en la gestión y en el desarrollo de un municipio que vaya más allá de una consulta cuatrienal en los momentos electorales.

Esta actitud, un tanto desidiosa, puede tener como principal razón el resquemor de los administradores políticos hacia las nuevas tecnologías, desde el punto de vista de la capacidad que estas aportan para una espectacular difusión de la opinión pública, la cual entraña (y los políticos lo saben) un aluvión de críticas, ya sean constructivas o no.

Por tanto, en esta posible reticencia se encuentra implícito el principal obstáculo por el cual los políticos no se plantean la posibilidad de crear una herramienta como es una página web que ofrezca una participación abierta de la ciudadanía. Existe un potencial riesgo de que la web se convierta en un mentidero donde todos hablan de todo sin orden ni concierto, valorando de forma negativa las actuaciones y gestiones de los administradores municipales.

Sin embargo, las nuevas tecnologías no solo han traído consigo la posibilidad de una propagación masiva de ideas, opiniones y conceptos. Hay una gran cantidad de instrumentos y recursos para poder mantener un cierto control sobre la página pero que, a la vez, pueda servir como cauce de participación constante de toda la ciudadanía, tanto en el ámbito colectivo como individual; lo que, sin duda, constituye, un claro avance para el desarrollo municipal.

\section{La selección en la participación}

Bien es cierto que no se puede dar rienda suelta en una página institucional a todo tipo de valoraciones y opiniones. No estamos hablando de censura previa, uno de los aspectos más deleznables en un Estado democrático. Nos referimos a filtros que no coarten la libertad de expresión pero que esta sea interpretada correctamente. En otras palabras: que la difusión de opiniones y críticas tengan un carácter constructivo y, en ningún caso, destructivo. La plena libertad para exponer opiniones puede traer como consecuencia casos como el del municipio de Tamames (Salamanca), que dispone de un foro que, bajo la denominación de Libro de Visitas, se reflejan ideas y comentarios desordenados y absolutamente 
inconexos entre sí. Este hecho lo único que genera es un "ruido" informativo sin aportar a cambio nada positivo, ni para el municipio ni para sus vecinos.

Determinados municipios se vieron obligados a retirar los recursos de participación: el Ayuntamiento de Cardenete (Cuenca) anuncia en su página la instalación de un sistema para que los usuarios del foro puedan ser identificados: "Con motivo de los últimos comentarios aparecidos en el presente foro que, amparándose en el anonimato, aprovechan para injuriar, calumniar y mentir, nos hemos visto en la obligación de cerrarlo temporalmente hasta que se consiga adaptar el sistema para que todo aquel que quiera escribir en el foro se tenga que identificar". Una situación similar se produjo en la localidad de Sancti-Spiritus (Salamanca), cuya página web anuncia: "hemos encontrado publicaciones de amenazas, insultos, mensajes que han podido violar la ley de protección de datos y afectar a personas ajenas a la corporación de este municipio".

Otro filtro puede ser la lectura previa por parte de un gestor antes de su publicación, como lleva a cabo el municipio de Valdemanco (Madrid), que lo anuncia del siguiente modo: "Sé amable y educado y evita usar palabras malsonantes. El administrador revisará todos los mensajes antes de publicarlos". La ventaja que tiene este tipo de filtro sobre el anterior es descartar cualquier posibilidad de crítica destructiva que, en el peor de los casos, obligue al ayuntamiento a demandar judicialmente a algún usuario. Pero, como contraposición, la lectura de los mensajes no es inmediata, hecho que puede coartar la participación del ciudadano.

\section{Eficacia y rapidez en la comunicación}

Para conseguir un fin correcto en la eficacia de la web, es preciso que el administrador sea rápido en su tarea de revisión de mensajes. Que no transcurra demasiado tiempo desde que el emisor lo transmite hasta que es publicado. Otras opciones que también requieren premura son los correos electrónicos, buzones de sugerencias y el resto de recursos similares que, en definitiva, su fin es idéntico y solo varía su denominación.

El Ayuntamiento de Guadalajara, a pesar de tener una de las páginas más participativas, contestó a nuestra solicitud de información casi un mes después de su emisión. Aseguraron en la respuesta que el correo fue abierto con retraso "debido a un problema organizativo, pero nuestra gestión es habitualmente mucho más ágil". Con una demora similar contestaron también desde Valencia; y otros, como el de Madrid, emitieron un acuse de recibo una semana después, y pasado algo más de un mes, recibimos la respuesta. Un caso contrario lo encontramos, por ejemplo, en el Ayuntamiento de Poboleda (Tarragona) o el de Valladolid, cuya respuesta fue prácticamente inmediata e incluso, en este último caso, utilizaron dos vías: el correo electrónico y el teléfono. 
Tanto la filtración como la publicación de las aportaciones vecinales, además de rápidas, deben estar generalizadas en la mayoría de los recursos participativos. No solo deben ser premisas básicas en un foro, sino también en la exposición de imágenes, como lleva a cabo el Ayuntamiento de Coria del Río (Córdoba); y en el resto de instrumentos que impliquen una aportación del usuario a la página web.

El gestor municipal no debería olvidar en ningún momento que una buena baza para transmitir confianza al ciudadano es escuchar sus impresiones, compartir con él las diferentes iniciativas que tengan que ver con el municipio, no solo las que supongan un avance en su desarrollo, sino aquellas que añadan un signo de identidad propio y que sea generado por el conjunto de la ciudadanía. La página web pública se puede convertir en un referente para el vecino y que el visitante esporádico encuentre un marco de referencia; no con valoraciones unilaterales procedentes de los organismos públicos, sino con la opinión que tengan los ciudadanos de a pie, ya sean residentes o no en ese municipio.

\section{Participación con innovación}

Elementos como la publicación de fotos, libros de visitas o textos alegóricos a la localidad, posibilitan el alcance de un doble objetivo: por una parte, conseguir una página web municipal con "personalidad" propia, que incluso sea el vivo reflejo de la idiosincrasia de esa localidad; $y$, por otra parte, que el ciudadano recurra habitualmente a la web oficial de su municipio. De este modo, el ayuntamiento, en su talante democrático, podrá lograr un fin esencial que, muy posiblemente, haya sido siempre un obstáculo porque no encontraba la vía para culminarlo: la implicación del ciudadano y el sentimiento de este para considerar que su esfuerzo es necesario si quiere que el municipio avance.

Además, la administración municipal podrá conseguir una comunicación fluida y directa con el ciudadano y no solo que este se movilice en una consulta electoral cada cuatro años. Las dimensiones que alcanzan los municipios hacen inviable una participación física directa en periodos más o menos cortos de tiempo. Por ello, la página web puede ser vista como un instrumento que reduzca esas distancias comunicacionales entre el ciudadano y los administradores públicos.

Los foros, chats y la introducción de elementos videográficos, son sumamente eficientes para poder conseguir la interactividad deseada. Pero existen también fórmulas novedosas que fomentan la identificación del usuario y que, con la correcta gestión, resultan sumamente eficientes y participativas. Un ejemplo de ello se ha encontrado en la página web de Guadalajara, con un vínculo que se esconde tras una particular denominación "Enwada" (http://enwada.es/ wiki/P\%C3\%A1gina_Principal ). Se trata de un proyecto de difusión cultural promovido por el ayuntamiento de esta localidad, y financiado con fondos europeos del Plan Avanza. 
Supone una valiosa herramienta cultural porque funciona con un sistema similar a la popularmente conocida Wikipedia. En este caso, los usuarios pueden aportar artículos referidos a todo lo que tiene que ver con la ciudad. La temática es numerosa y se divide en grandes áreas, a saber: Marco General, Estructura Urbana, Instituciones Locales, Política y Gobierno, Economía y Sociedad, Ciencia y Cultura, Historia y Periodos Históricos. Todos los artículos son sometidos a revisión por un grupo de editores, los cuales comprueban la pertinencia y corrección de los escritos enviados por los usuarios de forma voluntaria y desinteresada. Igualmente, se pueden enviar correcciones o ampliaciones de lo ya publicado con otros textos, pero también con imágenes, gráficos, mapas, etc.

Es, por supuesto, una forma de captar nuevos lectores de la página institucional y, por extensión, de un uso cada vez más frecuente. Otro modo para conseguir este objetivo es el propuesto por el Ayuntamiento de Barcelona. Se trata de una herramienta algo más prosaica que la descrita de Guadalajara pero con una efectividad similar. Su denominación ilustra plenamente a su contenido: "dedica una estrella en el firmamento virtual de Barcelona". El usuario puede escribir un mensaje a un ser querido que será añadido a una nueva estrella que se genera en una pantalla, en la cual se simula un cielo plagado de astros en una noche despejada. El destinatario del mensaje recibe un aviso en su correo electrónico con un vínculo añadido que enlaza directamente con la web institucional de Barcelona para que, de este modo, pueda ver su dedicatoria.

Paralelamente, hay una idea que plantean municipios como el de Jaca (Huesca) y el Ayuntamiento de León. Se trata de una iniciativa que, además de intentar captar a nuevos usuarios, ilustra las excelencias de ambas localidades. Nos referimos al Envío de Postales. La página dispone de algunas imágenes alegóricas del municipio y cada una de ellas ofrece un vínculo para poder ser reenviadas a direcciones de correos electrónicos de particulares. En Barcelona eran estrellas con mensaje; en Jaca y León son imágenes en forma de postal. En cualquiera de los casos, el objetivo es el mismo: dar a conocer la página web municipal al mayor número de internautas y no solo residentes en esos municipios.

\section{Interactividad y participación independiente al nivel poblacional}

Los índices poblacionales no pueden convertirse en una excusa para no implicar a los vecinos en la página web. Una amplia mayoría de administraciones con una territorialidad superior que la municipal han puesto en marcha, con mayor o menor acierto, diversas iniciativas para que todos los ayuntamientos tengan su sitio en la red.

Se han observado una gran cantidad de municipios que utilizan un modelo marco para el diseño de su web financiado, gestionado o patrocinado por su diputación provincial o por cualquier administración territorialmente más grande. 
Sin embargo, son escasas las webs de este tipo que plantean algunas señas de identidad propias. Todas se ajustan a un esquema común y en la mayoría de los casos no son completadas con contenidos elaborados por la administración municipal o por cualquier otro agente que tenga que ver con la localidad. Estas páginas suelen corresponder a los municipios de menor tamaño, cuyo índice poblacional no supera los 2.000 habitantes en el mejor de los casos.

Las reducidas dimensiones de una localidad pueden ser consideradas como una ventaja a la hora de elaborar una página web con unas señas de identidad propias. Por ejemplo, Valverde de Majano (Segovia), cuyo censo no alcanza el millar de habitantes, dispone en su página de una original sección que solo puede ser aplicable en las localidades de reducidas dimensiones. Felicita a los vecinos en el día de su cumpleaños. De esta forma se consigue un doble objetivo: primero, que la actualización se lleve a cabo prácticamente a diario; $\mathrm{y}$, segundo, que el vecino sienta como parte suya la web de su ayuntamiento, de su pueblo.

Son alternativas peculiares que, aunque no incentivan la participación activa del usuario en la página, sí que consiguen una conexión más personal y cercana entre la administración y el vecino. Este puede ser un punto de arranque para seguir avanzando hacia una implicación ciudadana mucho mayor en el desarrollo de la localidad, a través de un instrumento como el que aportan Internet y las nuevas tecnologías.

La implantación de medidas para conseguir un desarrollo sostenible y una reducción de los elementos contaminantes es otro de los objetivos que se han planteado en este siglo XXI. Algunos municipios han propuesto una iniciativa que, además de incentivar este tipo de medidas, fomentan la participación de los vecinos y la comunicación entre ellos. El proyecto se denomina Compartir coche. La idea consiste en que los ciudadanos con vehículo propio, y que todos los días realizan el mismo itinerario a su trabajo o a su lugar de estudios, puedan compartir el viaje con otros vecinos para distribuir gastos y evitar emisiones innecesarias de $\mathrm{CO} 2$. Desde la página web se ofertan los viajes o se solicitan itinerarios, hecho que invita a una participación activa y a que el usuario adopte la web municipal como una práctica herramienta para facilitarle su vida cotidiana. Son alternativas que no implican necesariamente un gran esfuerzo técnico o económico por parte de la administración municipal, solamente algo de voluntad para ponerlo en marcha y que sean los propios usuarios quienes lo hagan rodar.

De esta forma la interactividad, en mayor o menor grado, está garantizada con elementos originales que, además, suponen una implicación del vecino y aportan una imagen más positiva de la administración pública, sin que sus responsables puedan exponerse a riesgos relacionados a la introducción de contenidos indeseables. 


\section{E-Administración y correo electrónico como recursos de inicio, pero no exclusivos}

Del $58 \%$ de los ayuntamientos españoles que disponen de página web oficial, cerca de un 80 \% tienen activados dos recursos básicos: por un lado, la posibilidad de tramitaciones online, más conocida como E-Administración; y, por otro, la habilitación de una dirección de correo electrónico.

Ambas herramientas son adecuadas para que el ciudadano visite la página de su ayuntamiento y que inicie una fase de participación que invite a interactuar con la web; que no se limite únicamente a cliquear y ser un mero espectador pasivo de todo lo que le ofrece el administrador.

La E-Administración se encuentra desarrollada en varias fases dependiendo del municipio: unos solo se limitan a exponer documentos para su posterior presentación física en el ayuntamiento; y otros van más allá con la posibilidad de tramitar las gestiones por vía telemática, con o sin certificado digital.

Algunos de los municipios incorporan innovaciones, como es la inscripción en cursos o eventos y la venta de entradas para acontecimientos, entre otros. En determinados casos, plantean varias novedades como por ejemplo la localidad de Santa Olaya (Toledo), que facilita la tramitación de denuncias ante el cuerpo de seguridad de policía. Bajo el título de Policía-Net, ofrece una herramienta que no se ha visto en el resto de páginas analizadas. En cualquier caso, no deja de ser una variante de la E-Administración.

En cuanto al correo electrónico, se han visto también diversas alternativas: formularios-modelo o correos electrónicos dirigidos al alcalde, al servicio de atención ciudadana o a las diversas delegaciones que integran la gestión municipal. En algunos casos invitan a la participación con sugerentes denominaciones, tales como Gobierna con nosotros o Ayúdanos a mejorar.

Efectivamente son puntos básicos y piezas de arranque para la implicación ciudadana en la página municipal, pero no deben ser las únicas. Hay que ir más allá, al menos ofrecer alguno de los recursos que invitan a una mayor participación como pueden ser, entre otros, chats, elaboración de encuestas o foros. El impulso de aficiones o la potenciación de las tradiciones y signos culturales deben ser también uno de los instrumentos que, bien utilizados, pueden convertirse en la materia prima de la interacción.

Igualmente, es imprescindible la promoción del tejido asociativo y económico que constituyen grandes plataformas para la participación, y que incitan, a su vez, a la implicación del ciudadano. Tanto el tejido empresarial como el asociativo pueden aportar un contrapeso eficaz a la información meramente administrativa y pública. Por ello, sería deseable plantear en la página web un lugar destacado o, al menos, una de las secciones a estos colectivos. 
Uno de los principales valores en España es el turismo, hecho que también puede ser fomentado desde las administraciones más pequeñas territorialmente: los ayuntamientos. De este modo, no solo se podrá captar la participación del residente, sino también de usuarios del exterior, de los potenciales visitantes.

\section{Conclusiones}

Los ayuntamientos que sí disponen de página en la red no tienen como finalidad prioritaria entablar una relación comunicacional con el ciudadano, hecho que, ya hemos repetido en varias ocasiones, sería deseable. Las nuevas tecnologías, y en concreto Internet, ofrecen la posibilidad de establecer una relación entre administraciones públicas con un carácter intemporal y, a la vez, continuamente actualizada; globalizadora pero personalizada; $\mathrm{y}$, por último, eficaz y absolutamente interactiva en su más alto grado.

La escasa interactividad mostrada en las páginas web de los ayuntamientos españoles es originada por diferentes motivos que se pueden englobar en los siguientes:

- Baja disponibilidad de recursos para la comunicación multidireccional.

- Mínimos o, a veces, inexistentes aspectos complementarios que refuercen la eficacia de la web.

\section{Propuestas y aspectos para un modelo de página municipal interactiva}

La implicación constructiva de los ciudadanos en una web no debe ser tan compleja ni debe ser sometida a tantos obstáculos como ahora son generados. Para construir una base sólida en el fomento de la participación es preciso tener en cuenta diferentes aspectos:

1. A priori, deben plantearse unos filtros racionales que no supongan un obstáculo para la participación, pero sí que produzcan una interacción ordenada con opiniones constructivas y comunicaciones amplias y abiertas.

2. La rapidez en la respuesta, así como el mantenimiento continuo de la página son esenciales para que el vecino muestre interés y que la web municipal sea un referente de consulta habitual.

3. El fomento de las tradiciones como elemento integrador. La concienciación de un entorno social común entre los ciudadanos de un mismo municipio es básica en su desarrollo y avance. Que el usuario se sienta parte de un gran equipo con sentimientos y perspectivas comunes de cara al futuro. 
4. La potenciación de aficiones como elemento identificativo es crucial para conseguir el objetivo de la participación activa. Si estas son fomentadas por el ayuntamiento a través de su web, se podrá obtener una estrecha relación entre el administrador y el usuario.

5. Recursos innovadores como elementos de captación que si, por extensión, consiguen la participación, se podrán considerar muy positivos y eficaces para lograr la interactividad deseada y, por tanto, un cauce democrático en el que realmente todos se sientan parte implicada.

6. Promoción de los tejidos colectivos, principalmente de asociaciones e industrias, que constituyen piedras angulares en el desarrollo de la localidad.

7. Aprovechamiento de recursos tan enriquecedores como es, por ejemplo, el turismo para la captación de usuarios, que se puedan convertir en visitantes esporádicos o habituales.

8. Instrumentos para la búsqueda de soluciones a los problemas que más preocupan a la ciudadanía: el desempleo, el entorno ecológico o el desarrollo sostenible urbanístico, entre otros muchos.

9. Y, finalmente, iniciativas imaginativas y eficaces que den un "toque personal" a la página web municipal y, por extensión, a la gestión del ayuntamiento.

Todos ellos son aspectos que pueden ser impulsados por los gestores municipales. En caso contrario, el ciudadano optará por la desidia o por otras vías alternativas en las que sí se pueda escuchar su voz, opiniones e intereses.

\section{Referencias}

Arstein, S. R. (1969). A Ladder of Citizen Participation. Journal of American Institute of Planners (JAIP), 35(4), 216-224.

Baldersheim, H., y Øgard, M. (2008). Innovation in E-government: Analysis of municipal web pages in the Nordic countries. Information Polity, 13(3), 125-137.

Borge, R., Cardenal, A., y Malpica, C. (2012). El impacto de Internet en la participación política: Revisando el papel del interés político. Arbor, 188(756), 733-750.

García, B. (2011). Estudio sobre la interactividad en las web de los Ayuntamientos de España. Tesis doctoral dirigida por García Jiménez, Antonio). Madrid: Facultad de CC. Comunicación. URJC.

Chaín, C., Muñoz, A., y Más, A. (2008). La gestión de información en las sedes web de los Ayuntamientos españoles. Revista española de documentación científica, 31(4), 612-638. 
Correa, L. F. (2008). La Web 2.0. Colombia Universia.

Evans, M., y Campos, A. (2013). Open government initiatives: Challenges of citizen participation. Journal of Policy Analysis and Management, 32(1), 172-185.

Flores, C., y Rezende, D. (2013). Strategic Digital City: Techno-social Network Twitter as Communication Channel for Popular Participation in City Comprehensive Plans.

Freeman, A. (2013). An Ideal Model for Virtual Communication on Municipal Government Websites.

Lehtonen, P., y Mambere, J. (2013). Exploración temática con un panel ciudadano: el conocimiento comunicacional y de las TIC en una gobernanza participativa de la ciudad. En Coghlan, Juan Carlos Águila. Recensión del libro Citizen Voices, ECREA. Anuario electrónico de estudios en Comunicación Social Disertaciones, 6(1).

Levy, P. (2004). Inteligencia colectiva. Por una antropología del ciberespacio.

Llinares, J. (2010). Claves para entender la colaboración en el modelo Open Government. C. Calderón, y S. Lorenzo, Open Government, 51-74.

Margolis, M., y Resnick, D. (2000). Politics as usual. Sage Publications, Inc.

Nielsen, J. (2011). Participation inequality: Encouraging more users to contribute, 2006.

Norris, P. (2003). Digital divide: Civic engagement, information poverty, and the Internet worldwide. Cambridge, UK: Cambridge University Press.

Pineda de Alcázar, M. (2009). El papel de Internet como un nuevo medio de comunicación social en la era digital. Hipertextos, 6.

Regil, L. (2001). Interactividad en la construcción de la mirada. Infonomía. Barcelona.

Ros-Martín, M. (2008). Filtrado de la información en la Web: Basado en contenido, colaborativo y social. En Biblioteca 2.0.

Sádaba, C. (2010). El perfil del usuario de Internet en España. Intervención Psicosocial 19(1), 41-55.

Salinas, J. (1988). Interactividad y diseño de vídeos didácticos. Comunicación presentada al.

Surowiecki, J. (2005). Cien mejor que uno: la sabiduría de la multitud o por qué la mayoría siempre es más inteligente que la minoría. Urano.

Van. K., y Jan B. (2002). Towards a new classification of tele-information services. McQuail's Reader in Mass Communication Theory, 113. 
Voces-Merayano, R., y Codina, L. (2009). Web móvil y su implantación en la administración local española. El profesional de la información, 18(2), 211-217.

Zappen, P., Harrison, M., y Watson, D. (2008). A new paradigm for designing E-Government: web 2.0 and experience design. En Proceedings of the 2008 international conference on Digital government research. Digital Government Society of North America, 17-26. 